\title{
Serum cortisol in the early postoperative period as predictor of remission in Cushing's disease \\ of remission in Cushing's disease
}

Oliveira $\mathrm{J}^{1,4,5}$, Lau E ${ }^{1,4,5}$, Belo $\mathrm{S}^{1,4,5}$, Freitas $\mathrm{P}^{1,4,5}$, Vinha $\mathrm{E}^{1,4}$, Pereira $\mathrm{J}^{2,4}$, Castro $\mathrm{L}^{3,4}$, Carvalho $\mathrm{D}^{1,4,5}$

1Endocrinology, Diabetes and Metabolism Department; ${ }^{2}$ Neurosurgery Department; ${ }^{3 P a t h o l o g i c a l ~ A n a t o m y ~ D e p a r t m e n t ; ~}{ }^{4}$ Centro Hospitalar São João, Porto, Portugal;

${ }^{5}$ Faculty of Medicine of University of Porto, Portugal

\section{Introduction}

Pituitary surgery is currently considered the preferred treatment for Cushing's disease (CD) and achieves remission in $55-85 \%$ of patients. Cortisol falls after surgery, so that early postoperative cortisol level has been used as predictor of remission. There's no agreement about optimal timing for cortisol measurement, with wide variability between centers.

\section{Objective}

To assess the value of early (24hours) postoperative serum cortisol as predictor of remission after pituitary surgery in Cushing's disease.

\section{Methods}

Cross-sectional, retrospective study of patients who underwent pituitary surgery for CD between January/1998-October/2013. No glucocorticoid replacement therapy was initiated until blood samples were drawn (8 a.m. the day after surgery).

$\checkmark$ Serum cortisol (normal range: $7-25 \mu \mathrm{g} / \mathrm{dL}$ ), ACTH (normal range: $<63.3 \mathrm{ng} / \mathrm{L}$ ), urinary free cortisol (normal range: $75-270 \mu \mathrm{g} / 24 \mathrm{~h}$ ).

$\checkmark$ Remission was defined as restitution of normocortisolemia or development of hypocortisolism requiring glucocorticoid replacement.

\section{Results}

53 patients

Insufficient data

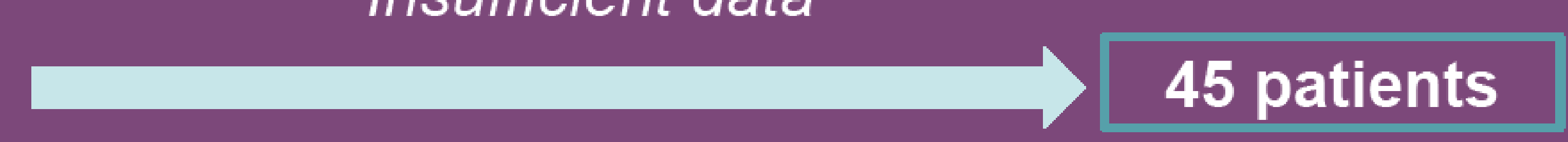

$\begin{array}{ll}\text { n } & 45 \\ \text { Age [years, mean (SD)] } & 38.2(12.9) \\ \text { Sex [n (\%)] } & \\ \quad \text { Male } & 6(13.3 \%) \\ \quad \text { Female } & 39(86.7 \%) \\ \text { Follow-up [months, mean (SD)] } & 90.4(56.7)\end{array}$

After pituitary surgery:

$\checkmark 33$ patients $(73.3 \%)$ achieved cure

$\checkmark 12$ patients $(26.7 \%)$ presented persistent disease

$\checkmark 10$ patients relapsed $(30.3 \%) \rightarrow$ mean follow-up time until relapse of $64.4 \pm 36$ months

BASAL HORMONAL MEASUREMENTS

\begin{tabular}{|c|c|}
\hline ACTH [ng/L, mean (SD)] & $75.9(41.3)(n=40)$ \\
\hline Serum cortisol [jg/dL, mean (SD)] & $27.5(10.9)(n=39)$ \\
\hline Urinary free cortisol [jg/24h, mean (SD)] & $456.3(406.2)(n=40)$ \\
\hline Cortisol - Overnight dexametasone supression test [Mg/dL, mean (SD)] & $22.8(15.5)(n=12)$ \\
\hline
\end{tabular}

CRH TEST

MAgNetic Resonance IMAging

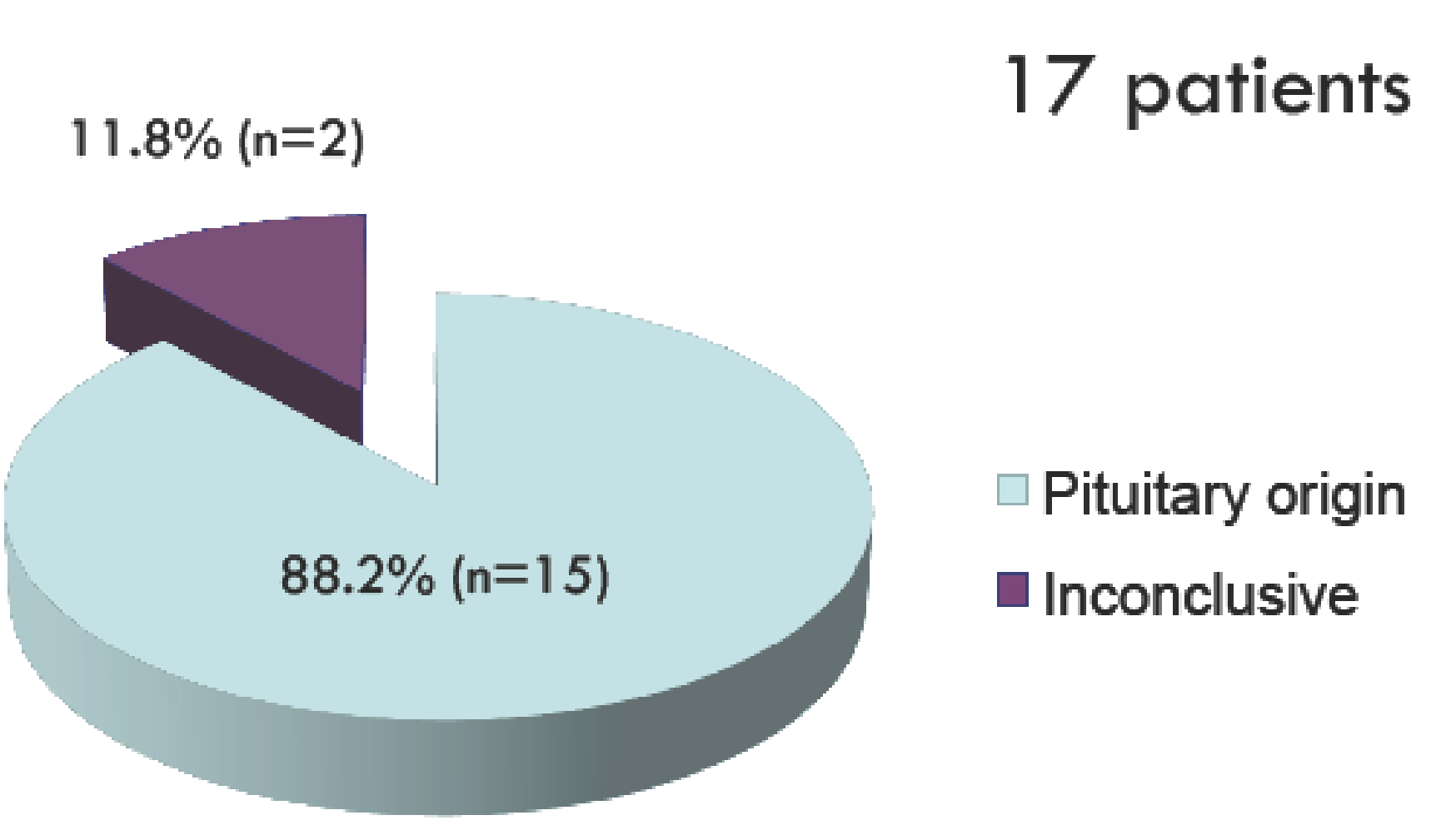

MAGNETIC RESONANCE IMAGING
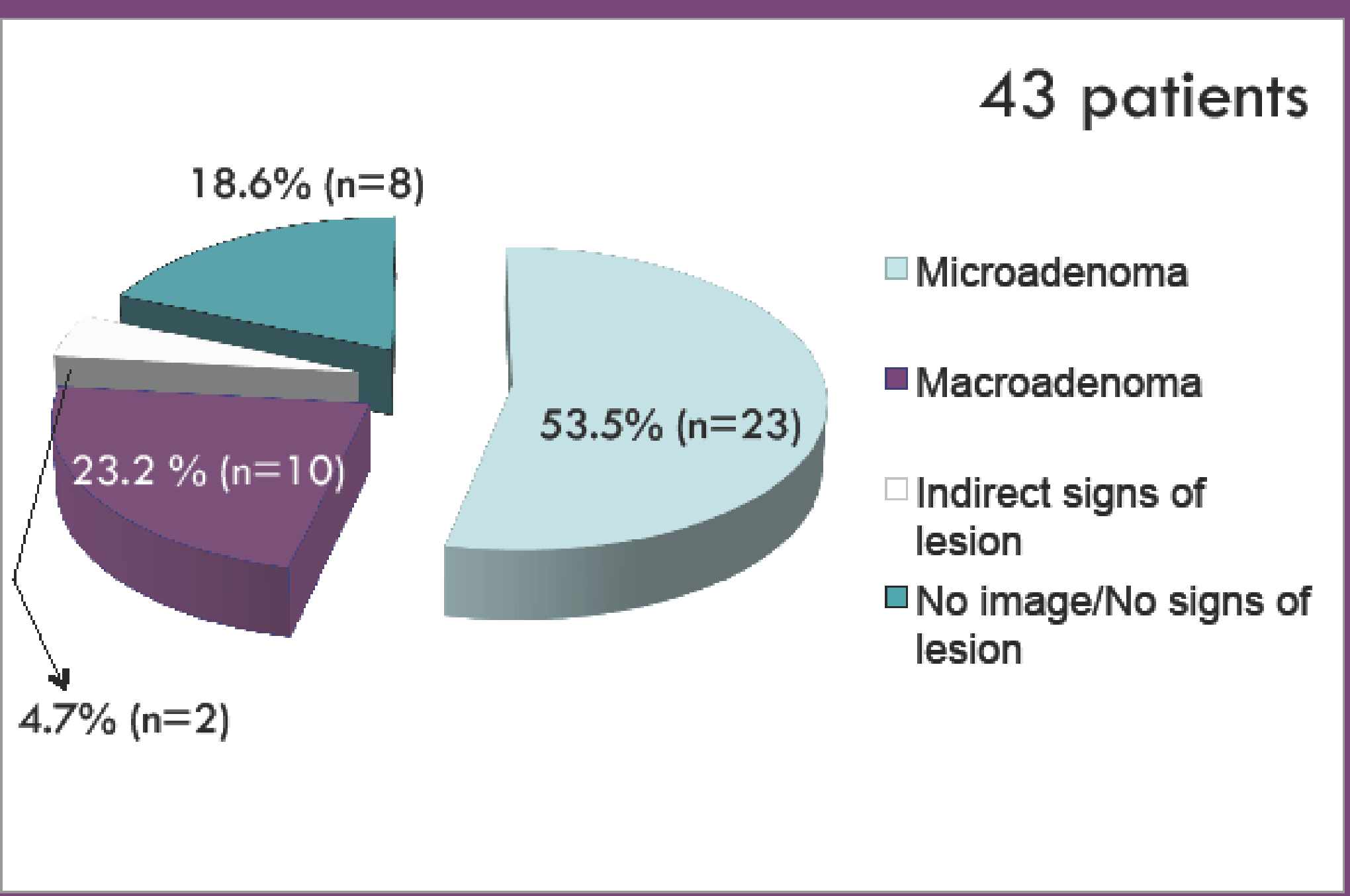

No significant differences in urinary free cortisol, ACTH, serum cortisol and cortisol in the overnight dexamethasone suppression test at diagnosis between patients with and without disease remission after surgery, or between patients with and without disease recurrence.

INFERIOR PETROSAL SINUS SAMPLING

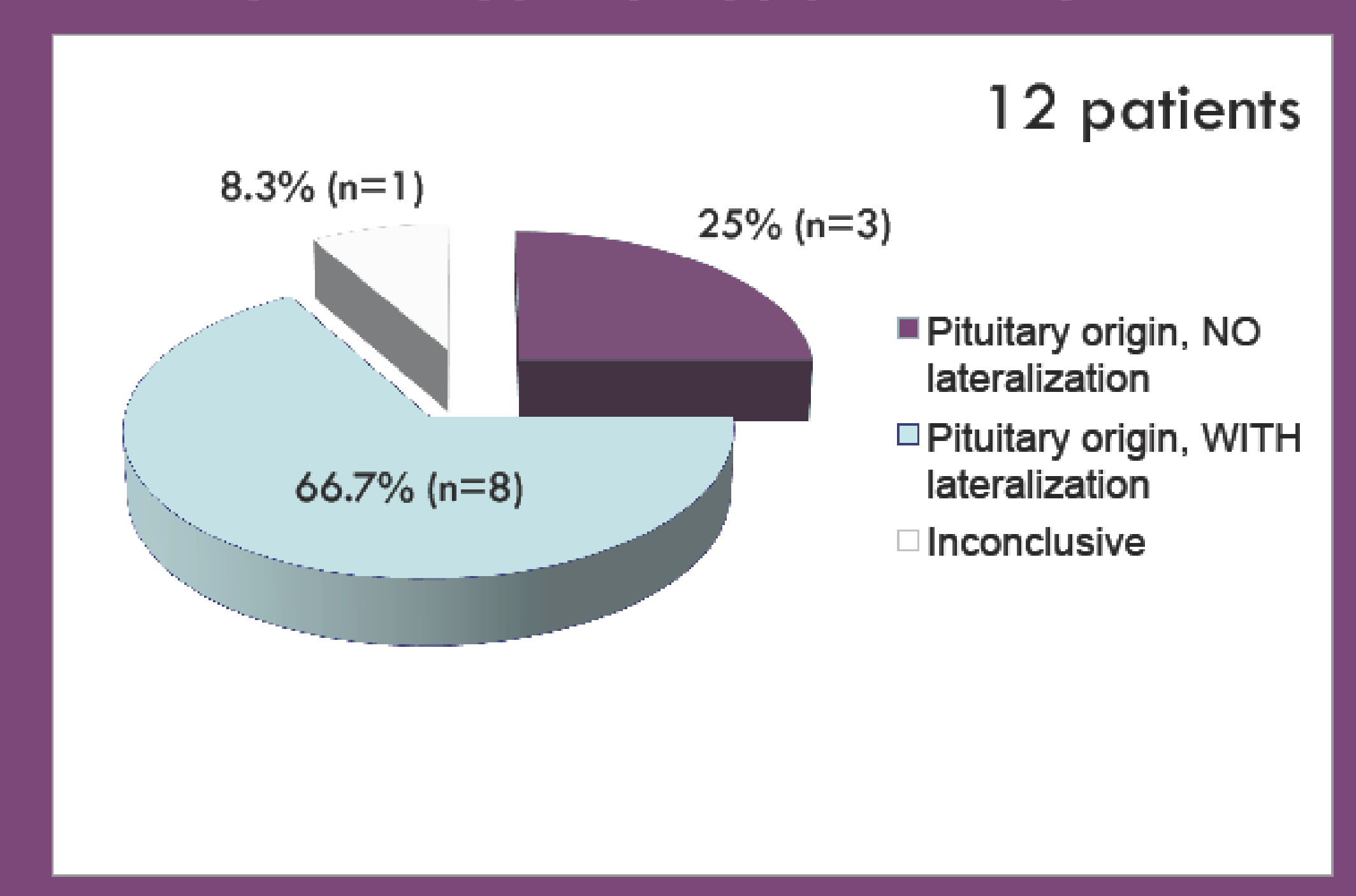

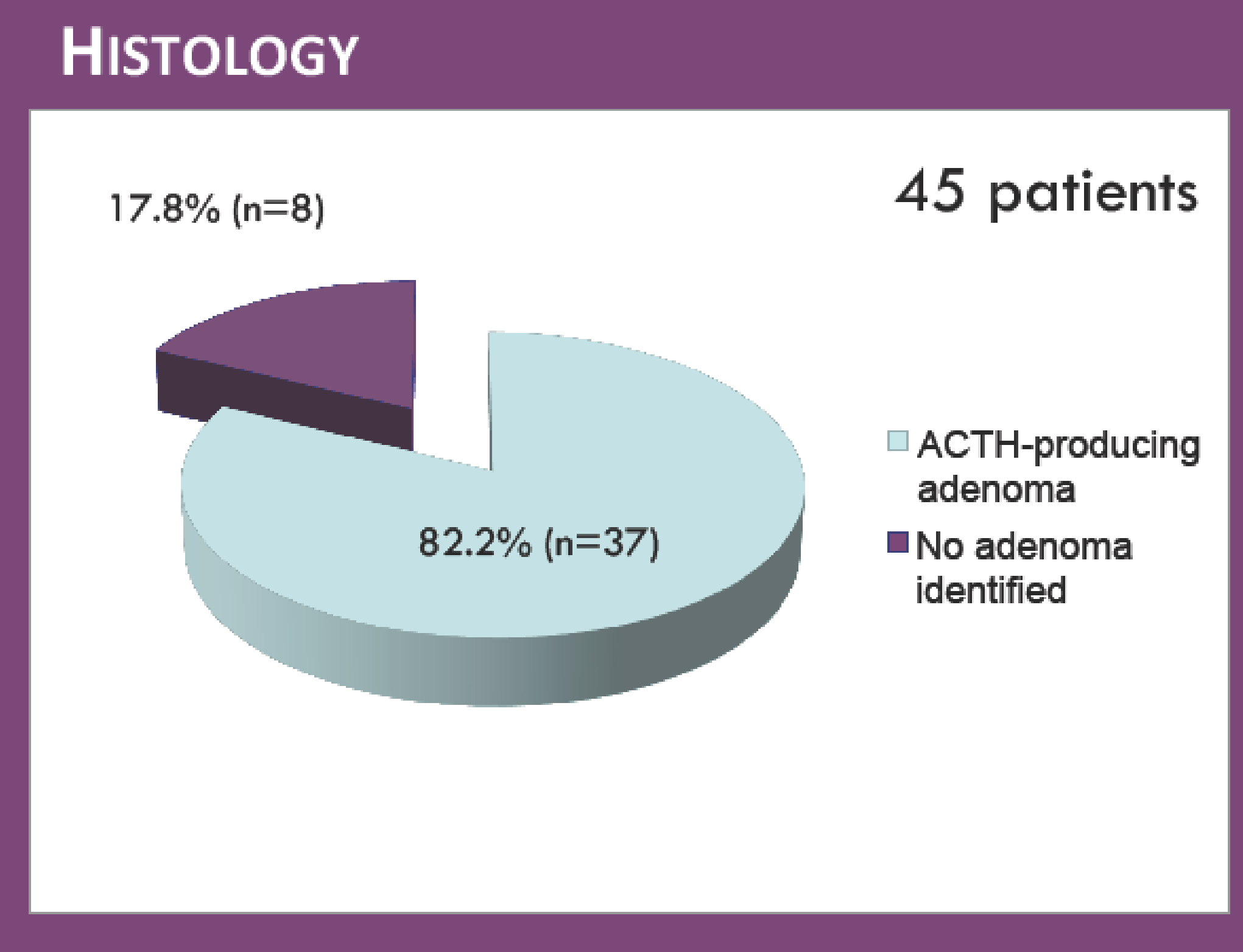

Despite this difference, the postoperative serum cortisol was not a good predictor of remission of $C D$ $\underline{(A \cup C<0.5)}$.
36 patients with morning serum cortisol the day after surgery

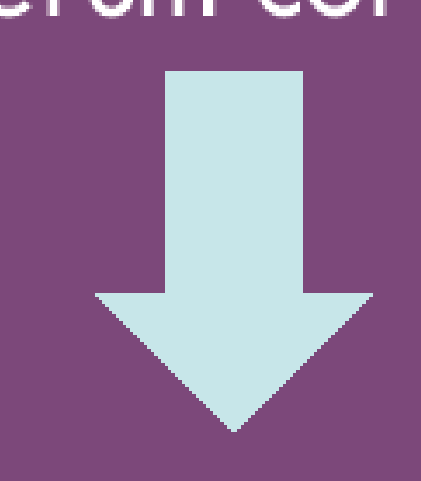

26 patients $\rightarrow$ remission after surgery

10 patients $\rightarrow$ persistent disease after surgery

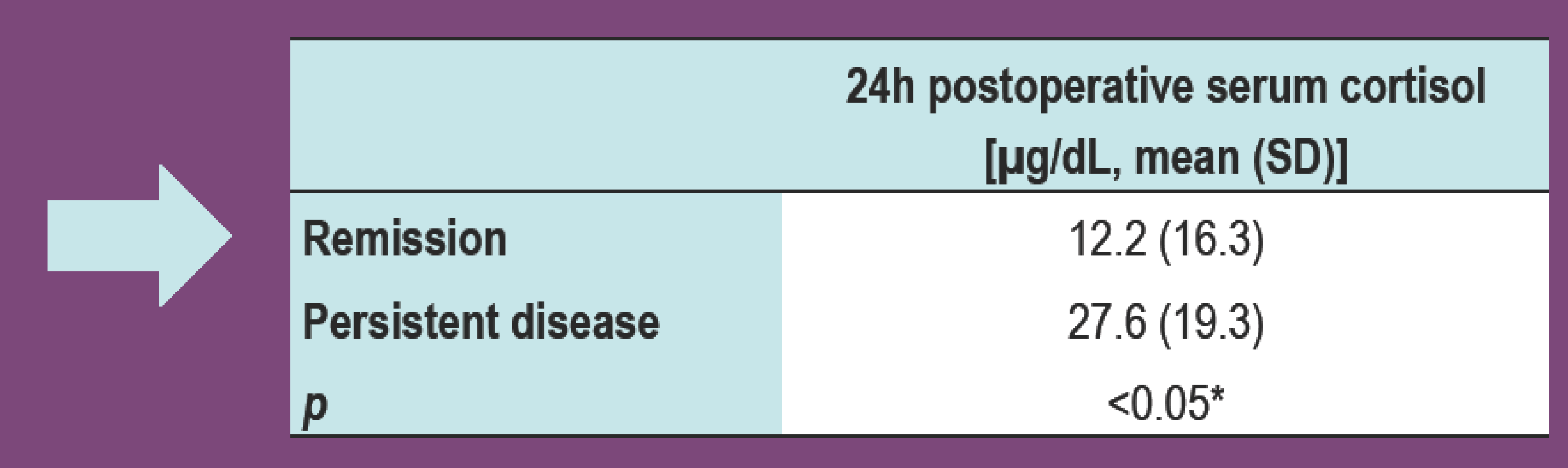

\section{Discussion/Conclusion}

Previous studies demonstrated that some patients have a delayed decrease to normal or low cortisol levels, without immediate postoperative remission. That could be explained by a gradual resolution of adrenal autonomy after pituitary adenoma resection, especially in the presence of significant bilateral hyperplasia. Moreover, gradual decline in cortisol during early postoperative period could be related to delayed adenoma necrosis. In our cohort, serum cortisol measured at 24 hours after pituitary surgery was not predictive of remission of $\mathrm{CD}$. A longer interval between surgery and hormonal evaluation may allow a more accurate classification of these patients, including those with later remission. 